\title{
G
}

\section{Examples of Presenting EMDR Therapy During Phase 2}

\author{
E. C. Hurley, DMin, PhD
}

Introduction: This page provides scripted examples for introducing EMDR therapy to military and veteran clients. The examples are not set in concrete but offer examples that have been used for several years while treating military and veteran clients. They are offered as examples that can be used for therapists to develop their own script during their clinical treatment with these populations.

Therapist: The initial introduction emphasizes the recognition of EMDR therapy among international professional organizations. Then, "Phase 2: Setting up the mechanics" presents a way of introducing eye movement to clients who can comfortably perform eye movements (EM). Recognize that some persons with brain damage (TBIs) may have difficulty with EM, requiring other modalities of bilateral stimulation (BLS). Demonstrating the impact of slow EM to the parasympathetic nervous system for calming down or helping the client relax is helpful for the client to gain an experiential understanding of BLS. Presenting an introduction in this manner, during Phase 2, develops confidence in both the use of EM and the client's ability to relax. Of course, when the client feels vulnerable in relaxing, the therapist must first work with security/vulnerability issues before addressing the relaxation of the client.

Informed consent offers the client a basic description of what to expect at the beginning with asking the seven questions in the Assessment phase along with the request for brief feedback, noting that EMDR therapy is unlike talk therapy. You, as the therapist, only need a word, phrase, or sentence to see if the memory is changing before saying, "Go with that!" which means "start back up where you just left off." 
Client: These scripts provide a basic structure for introducing EMDR therapy with its BLS to the client, allowing them know what to expect next in the treatment process.

\section{INTRODUCING EMDR THERAPY_USUALLY PROVIDED TOWARD THE LAST PART OF PHASE 1: HISTORY-TAKING}

"EMDR therapy is a model of psychotherapy I frequently provide to many clients. Its effectiveness is recognized by numerous professional organizations including the World Health Organization (WHO), the Department of Veterans Affairs, and Department of Defense, and numerous organizations worldwide. It has been found helpful for many persons dealing with similar issues as yourself. I think it could be helpful to you if you are willing to give it a try."

\section{PHASE 2: SETTING UP THE MECHANICS}

"I have learned that if I hold up my fingers and your eyes slowly follow them about 6 to 8 times, your body will begin to relax. And, if I speed up the movement, you will begin to process your memories faster. Are you okay if I hold up my hand and your eyes follow my fingers slowly to relax?" (Do 6-8 repetitions of EM slowly and gradually increase speed for a couple sets.) "Take a breath, let it go. What do you notice? Let's do it again." Do this three or four sets, having the client take a deep breath after each set. "How was that?"

(Introduce auditory and tactile) "Which one of these-eye movement, auditory, or tactile-work best for you?"

\section{E. C. HURLEY'S INFORMED CONSENT WHEN WORKING WITH MILITARY/VETERANS AND FIRST RESPONDERS}

(After the Phase 2 relaxation exercise-just before beginning Phase 3 Assessment)

I am going to ask you seven questions about how the incident/event is impacting you now. Each question is designed to access a different part of your memory regarding the incident. I don't need a lot of details about what happened, just what you want to share with me in response to my questions. Following the seven questions, I will do what we call bilateral stimulation (EM, tactile, auditory) for about 30 seconds each time. I will stop and ask you for feedback such as "What do you notice?" or "What do you get now?" I am ask- 
ing about what is different about the memory. This is not like talk therapy-all I need is a word, phrase, or a sentence telling me what is changing about the memory. I need as clear of feedback as possible. Just observe your experience and report it to me. Whatever you say, I will say "Go with that," which means resume or start up where you left off a minute ago. We will do this for a period of time until thinking about the incident no longer bothers you. Would this be okay that you are over it and it no longer bothers you? (Pause)

You are in control of the process. You have your stop signal should you need to stop as well as your relaxation exercise should you need to calm down. You may or may not experience some intense emotional response. Should this happen I will not leave you in the middle of it-my job is to get you through it. It is information you have bottled up and carrying with you. Should it happen, it usually only lasts 2 to 5 minutes and you will be over it. This is like a safety briefing; just because we are talking about it does not mean it will happen, but if it does, we know what to do. Are you okay with this?

(Begin Phase 3 Assessment) 